\title{
Chromosomal markers in three species of the genus Mytilus (Mollusca: Bivalvia)
}

\author{
A. MARTÍNEZ-LAGE, A. GONZÁLEZ-TIZÓN \& J. MÉNDEZ* \\ Departamento de Biologia Celular y Molecular, Area de Genética, Universidad de La Coruña, 15071 La Coruña, Spain
}

\begin{abstract}
The analysis of C-banding, NOR and fluorochrome staining was carried out in three species of European mussel, Mytilus edulis, $M$. galloprovincialis and $M$. trossulus. The results obtained allow us to detect changes in the constitutive heterochromatin within the genus Mytilus. The existence of chromosomal markers permit us to identify and distinguish, at the cytogenetical level, these three types of mussel.
\end{abstract}

Keywords: C-bands, chromosome markers, CMA3 bands, heterochromatin, Mytilus, NORs.

\section{Introduction}

The genus Mytilus is the subject of an important controversy about the systematic status of the different forms within it. In this genus, taxonomic studies were initially developed in order to establish a systematic relationship between $M$. edulis and $M$. galloprovincialis and, later, among other forms of mussels. At first, the studies were focused on morphological criteria and morphometric parameters (internal and external shell characteristics, the anterior adductor muscle features, etc.). However, as pointed out by Seed (1968), such characters are enormously plastic, being influenced by factors such as the age of the mussels, the density of the population, the tidal level and habitat type, and even then they have not allowed identification of the different types of mussels. Later, samples of mussels from different geographical regions in the northern and southern hemispheres were electrophoretically analysed. Different loci were studied, but none of them was truly diagnostic; namely none allowed assignment of a particular sample to a particular species. However, the results obtained after studying several loci per individual and a great number of individuals per population have allowed us to characterize different populations and to discriminate between different mussel types within the genus Mytilus (Koehn, 1991; Gosling, 1992).

According to these data, it is considered that there are three species of mussel within the genus Mytilus distributed along European coasts. $M$. edulis is distributed along the Atlantic coast of Europe; M. galloprovincialis appears to be distributed along the Mediterranean coast, the French Atlantic coast and

*Correspondence. along various coastal regions of the British Isles. Subsequently, in France, Britain and Ireland, M. galloprovincialis has been found to be intermixed with $M$. edulis, producing hybrid forms (Skibinski \& Beardmore, 1979). M. trossulus is distributed in the Baltic Sea. In the Danish straits, $M$. trossulus is intermixed with $M$. edulis (Väinölä \& Hvilsom, 1991).

On the other hand, studies using Mytilus cytogenetics have shown that the diploid number is 28 chromosomes (Ahmed \& Sparks, 1970; Ieyama \& Inaba, 1974; Thiriot-Quiévreux \& Ayraud, 1982; Moynihan \& Mahon, 1983; Dixon \& Flavell, 1986; Pasantes et al., 1990), and were confined to the descriptions of the nucleolar organizer regions and the location of heterochromatin in M. edulis (Dixon et al., 1986; Dixon \& McFadzen, 1987). In M. galloprovincialis a $2 \times$ SSC banding pattern has been induced by Méndez et al. (1990) and NORs were described by Martínez-Expósito et al. (1994) in four populations of La Coruña (Galicia, NW Spain) and cytogenetic characterization by means of C-banding, fluorochromes and restriction endonucleases has been carried out by Martínez-Lage et al. (1994).

In the present paper we describe the differences among $M$. edulis, $M$. galloprovincialis and $M$. trossulus on the basis of C-, NOR and fluorescence banding in order to detect possible chromosome markers which will allow us to identify, at the individual level, the different mussel types.

\section{Materials and methods}

Taking into account the distribution of the genus Mytilus along the European coasts, we have collected samples from places where hybrid forms have not been detected. So, individuals of $M$. edulis were collected 
from Zoutelande (Zeeland, Holland), individuals of $M$. galloprovincialis from Ría de Betanzos (La Coruña, Spain) and individuals of $M$. trossulus from Dahme (Mecklenburger Bay, Germany). The process of fertilization and culture was carried out as described by Martínez-Lage et al. (1994), from six females and five males of $M$. edulis, 10 females and 10 males of $M$. galloprovincialis, and five females and seven males of M. trossulus.

The C-banding method (Sumner, 1972) was used for constitutive heterochromatin localization; metaphases were stained with acridine orange $(\mathrm{AO})$ in Sörensen's buffer $(0.06 \mathrm{M}, \mathrm{pH}$ 6.5) for 5 min. Silver nitrate staining was performed according to Howell \& Black (1980). Fluorescence analysis was carried out using quinacrine (Cassperson et al., 1968); chromomycin A3 (CMA3), dystamicin (DA) and 4'-6 diamidine-phenyl indole (DAPI) according to the methods developed by Schweizer (1976, 1980).

Metaphase chromosomes were observed and photographed with a Nikon microphot AFX microscope. For fluorescence, the Nikon filters employed were UV$1 \mathrm{~A}$ (AD/DAPI), BV-1A (CMA3) and B-2A (AO).

\section{Results}

\section{Giemsa karyotype}

The karyotypes of $M$. edulis, M. galloprovincialis and $M$. trossulus comprise six pairs of metacentric and eight pairs of submeta-subtelocentric chromosomes (Fig. 1).

\section{C-banding}

In these three species, some differences exist in the C-bands distribution. In $M$. galloprovincialis, as previously reported by Martínez-Lage et al. (1994), C-bands appear on chromosomes $1,3,5,6,7,9,12$ and 13. M. edulis and $M$. trossulus show the same location of C-bands; these are located on chromosomes 1, $3,5,6,7,8,12$ and 13 . Table 1 shows the localization of the C-bands in these species. We observed that the main differences involved chromosomes $1,3,6,8$ and 9 (Fig. 2; Table 1). These differences are: (i) the presence of one centromeric and two telomeric bands in chromosome 1 of $M$. edulis and $M$. trossulus, which are replaced by an interstitial one in $M$. galloprovincialis; (ii) chromosome 3 from $M$. edulis and $M$. trossulus shows telomeric C-bands on the $\mathrm{p}$ arm, which are absent in $M$. galloprovincialis; (iii) the intercalary C-band of chromosome 6 fails to appear in M. edulis and $M$. trossulus; (iv) the telomeric C-band of chromosome 8 appears in $M$. edulis and $M$. trossulus but not in M. galloprovincialis; and (v) M. galloprovincialis shows
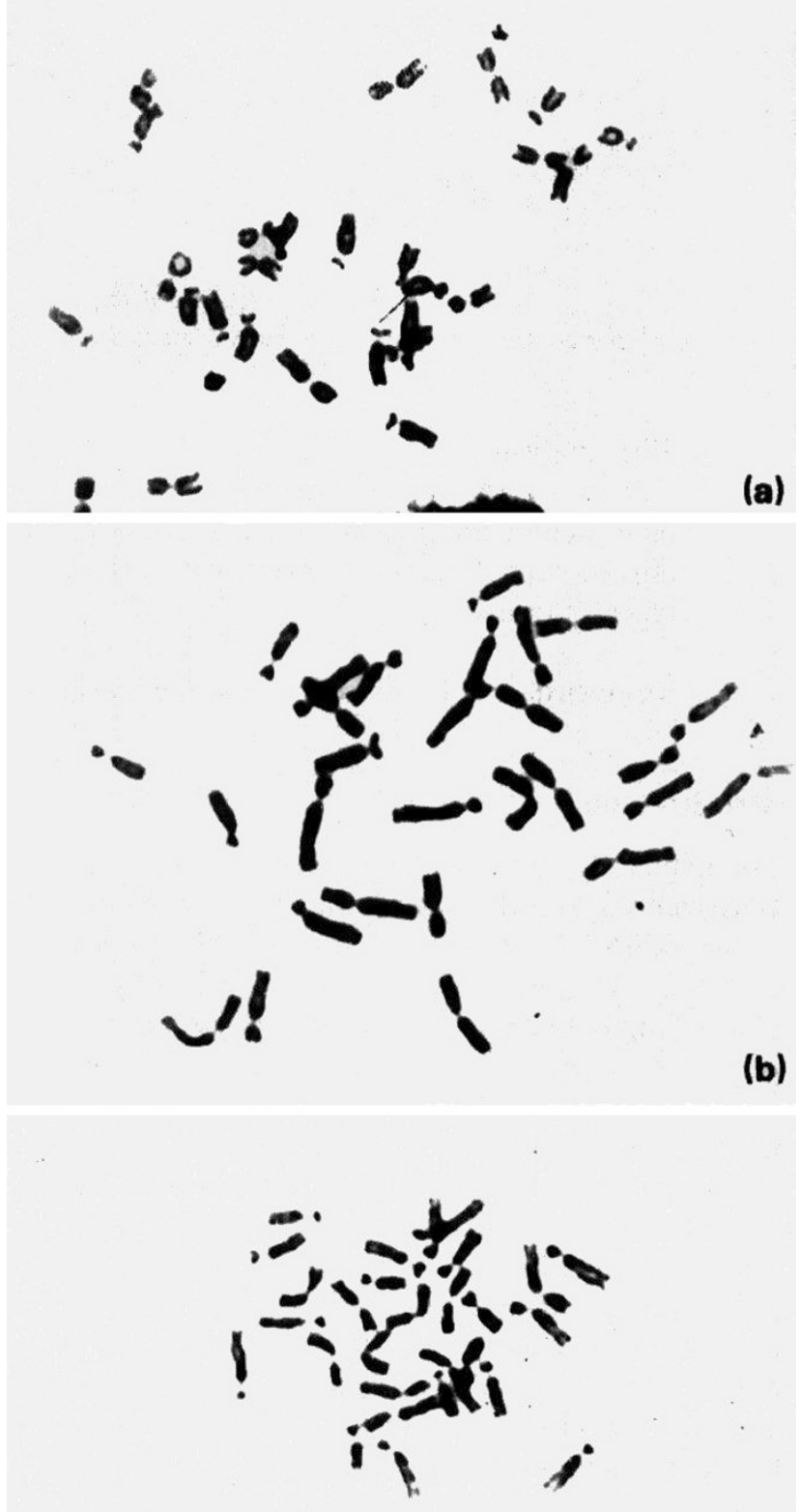

(c)

Fig. 1 Giemsa metaphase plates from Mytilus edulis, $M$. galloprovincialis and M. trossulus.

a telomeric C-band on chromosome 9, which is absent in the other species.

\section{NOR silver staining}

Forty larval metaphases of each mussel species were analysed. We have detected a variable number of AgNORs, which varied from two to four in $M$. edulis and $M$. galloprovincialis, and from two to five in $M$. trossu- 
Fig. 2 C-banding and comparative idiograms of the three European mussel species. e, Mytilus edulis; $\mathrm{g}, M$. galloprovincialis; $\mathrm{t}, M$. trossulus; chro. no., chromosome number; ${ }^{* * *}$, absence of banding.

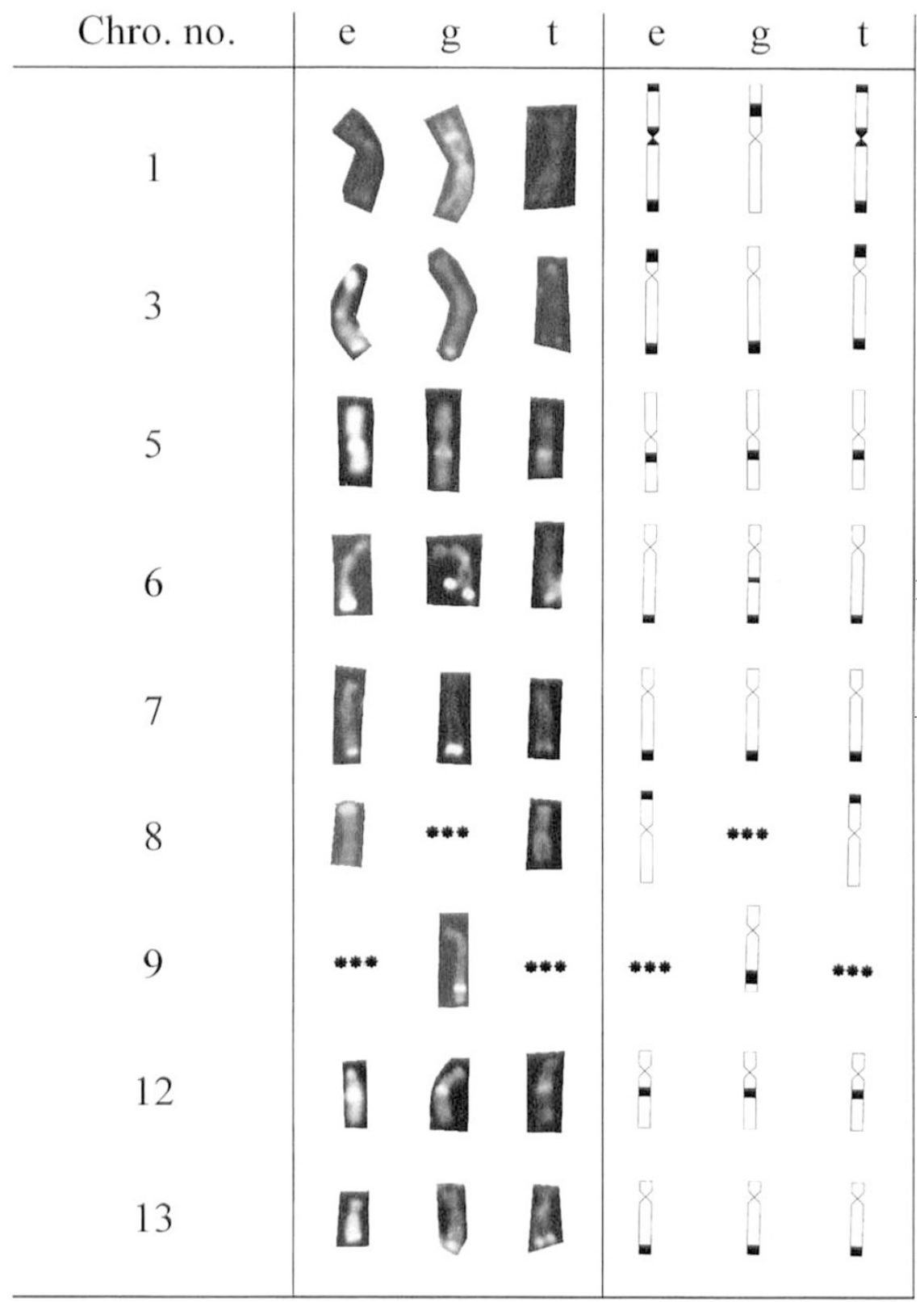

lus. The silver-stained karyotypes of the three species show chromosomal pairs 6 and 7 (submeta-subtelocentrics) with telomeric NORs (Fig. 3a,c,e). In $M$. trossulus, a third additional NOR appears located on the $\mathrm{p}$ arm of metacentric chromosome 8 (Fig. 3e, Table 2).

\section{Fluorochrome staining}

Telomeric CMA3 bands were found on chromosomes 6 and 7 in each one of the three mussel species (Fig. 3b,f,g; Table 2). In $M$. galloprovincialis, a third telomeric CMA3 band appears located on the $p$ arm of chromosome 3 (Fig. 3d).
DA/DAPI produced a negative response on the chromosomes, which was accompanied by a decrease of the staining in the telomeric regions of chromosomes 6 and 7 from the three species (Fig. 3g,h). Similarly, Q staining (Fig. 3i) revealed a negative response in each of the species.

\section{Discussion}

The genus Mytilus is a complex of closely related species which share the same basic karyotype in terms of external chromosome morphology. When we examined metaphases from $M$. edulis, $M$. galloprovincialis and $M$. trossulus, we observed an uniformity of 
Table 1 Distribution of C-bands in mussel species

\begin{tabular}{cccc}
\hline C. no. & M. edulis & M. gallopro & M. trossulus \\
\hline $1 \mathrm{p}, \mathrm{t}$ & $*$ & - & $*$ \\
$1 \mathrm{p}, \mathrm{i}$ & - & $* * *$ & - \\
$1 \mathrm{c}$ & $*$ & - & $* *$ \\
$1 \mathrm{q}, \mathrm{t}$ & $*$ & - & $*$ \\
$3 \mathrm{p}, \mathrm{t}$ & $* * *$ & - & $*$ \\
$3 \mathrm{q}, \mathrm{t}$ & $* *$ & $* *$ & $*$ \\
$5 \mathrm{q}, \mathrm{i}$ & $* * *$ & $* *$ & $* *$ \\
$6 \mathrm{q}, \mathrm{i}$ & - & $* *$ & - \\
$6 \mathrm{q}, \mathrm{t}$ & $* * *$ & $* * *$ & $*$ \\
$7 \mathrm{q}, \mathrm{t}$ & $* *$ & $* * *$ & $*$ \\
$8 \mathrm{p}, \mathrm{t}$ & $* *$ & - & - \\
$9 \mathrm{q}, \mathrm{t}$ & - & $* * *$ & $* *$ \\
$12 \mathrm{q}, \mathrm{i}$ & $* * *$ & $* * *$ & $* *$ \\
$13 \mathrm{q}, \mathrm{t}$ & $* *$ & $* *$ & \\
\hline
\end{tabular}

***, strong bands; **, intermediate bands; *, dull bands; - no banding; $\mathrm{p}$, band on $\mathrm{p}$ arm; $\mathrm{q}$, band on $\mathrm{q}$ arm; $\mathrm{t}$, telomeric band; c, centromeric band; i, interstitial band; C. no., chromosome number.

chromosome number, relative chromosome size and centromere position.

According to our previous report on M. galloprovincialis (Martínez-Lage et al., 1994), C-banding analysis confirms that these three species possess small amounts of constitutive heterochromatin which is located, mainly, in the telomeres and interstially, and very rarely located on centromeres. After C-banding, chromosomes from $M$. edulis and $M$. trossulus exhibit 11 blocks or regions of constitutive heterochromatin, and $M$. galloprovincialis only shows nine heterochromatin regions (Fig. 2; Table 1). The more remarkable differences in C-bands among these species are related to chromosome 1 from $M$. galloprovincialis, which only shows an interstitial C-band, whereas $M$. edulis and $M$. trossulus show two telomeric and one centromeric C-band (Fig. 2; Table 1). Furthermore, in $M$. galloprovincialis, the loss of the heterochromatic $\mathrm{C}$-bands on the $\mathrm{p}$ arms of chromosomes 3 and 8 and the gain of the interstitial C-band on chromosome 6 and the telomeric one on chromosome 9 reflect some changes in the heterochromatin of these species in the course of divergence from $M$. edulis.

It is assumed that the differences in the amount and location of constitutive heterochromatin is a mechanism of karyotype differentiation. In this sense, some models have been proposed to explain these changes or variations in heterochromatin. King (1980) and, later, other authors predicted that the differences in C-bands could be attributed to the addition or loss of heterochromatin; this process may be accompanied by chromosomal rearrangements such as fusions or fissions which would alter the morphology of the chromosome complement. Such types of changes have been described by Mayr et al. (1985) in mammals and by John et al. (1985) in grasshoppers. However, in mussels, we have not observed differences in the chromosome length or morphology between the species studied; our results suggest that this mechanism is not involved in the differentiation of the karyotypes. The second mechanism postulates the transformation of heterochromatin to euchromatin (or the reverse), which would involve internal transformation changes. This process seems to be uncommon, but it has been described in rats by Yosida \& Sagai (1975), in orthopterans by Camacho et al. (1981) and in crocodiles by King et al. (1986). Initially, our results suggest that the differences in the $\mathrm{C}$-banding patterns between $M$. edulis-M. trossulus and $M$. galloprovincialis could be produced by a heterochromatin-euchromatin transformation process. As we have pointed out, there are changes in the heterochromatin but chromosomal rearrangements do not exist.

On the other hand, the C-bands of the Mytilus species analysed in this paper do not show centromeric location (except for chromosome 1 from $M$. edulis and $M$. trossulus). To explain the location and distribution of the heterochromatic regions, Macgregor \& Sessions (1986) propose that the centromeres are C-band initiation sites from which a heterochromatin transference takes place towards the telomeres and, therefore, karyotypes with more telomeric heterochromatin have an older phylogenetic status. In this sense, the presence of more telomeric bands in $M$. edulis than in $M$. galloprovincialis corroborates the phylogenetic data which indicate that $M$. edulis has an older evolutionary status.

The analysis of NOR regions revealed the functional location on the telomeres of chromosomes 6 and 7 in each one of the mussel species. In $M$. trossulus a third additional single NOR was located on the telomere of metacentric chromosome 8. A clear coincidence between C-banding and NORs is detected in chromosomes 6 and 7 from the three species and in chromosome 8 from $M$. trossulus. Furthermore, CMA3 staining reveals a positive response on the NOR regions of chromosomes 6 and 7 in the three species. A third positive CMA3 band appears on the short arm of chromosome 3 in $M$. galloprovincialis, but it does not appear to be an active NOR. The additional NOR detected in $M$. trossulus appears to be CMA3 negative.

Some possible mechanisms have been postulated to explain the appearance of new NORs in species. One of the most common suggests the activation of latent NORs, which take over the primary nucleolar function under certain conditions or in certain genomes (King, 
Fig. 3 NORs and CMA3 bands in Mytilus edulis (a,b), M. galloprovincialis (c,d) and M. trossulus (e,f). In (3e) the wide arrow identifies the additional single NOR. (g,h) absence of staining on the telomeric regions of chromosomes 6 and 7 from $M$. edulis after DA/ DAPI staining. (i) metaphase from $M$. galloprovincialis after quinacrine staining.
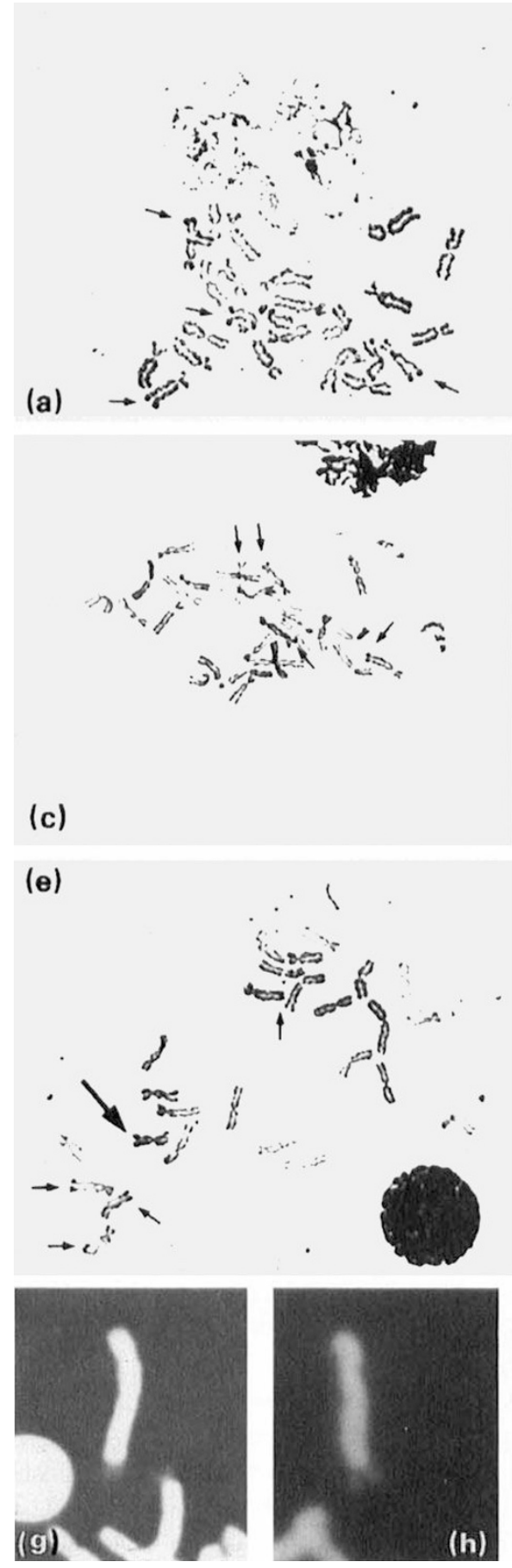
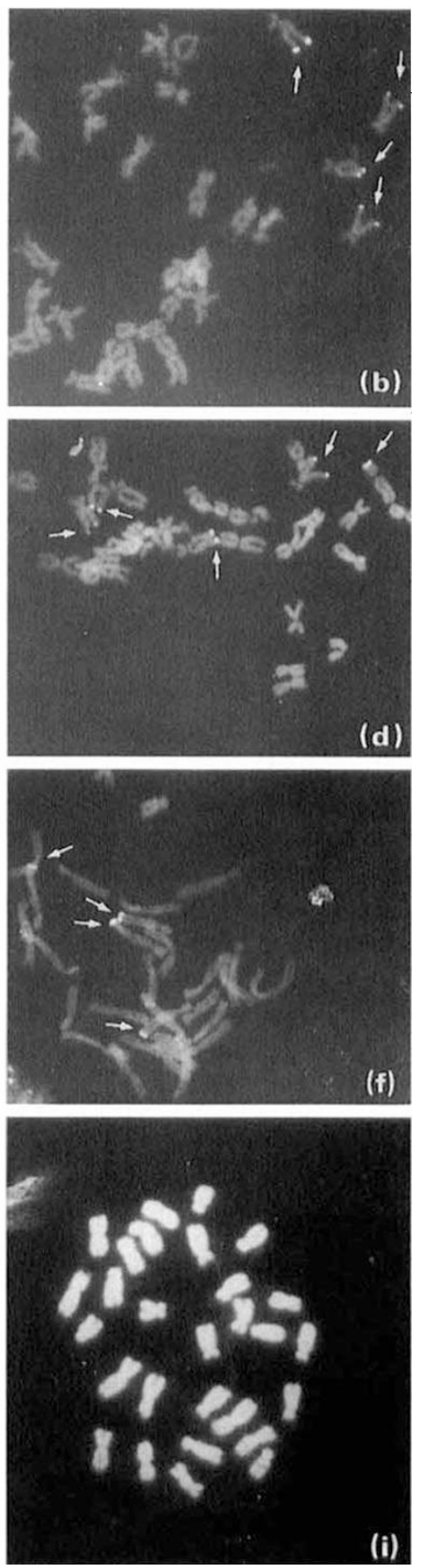

1980; Verma \& Raina, 1981; Fernández-Piqueras et al., 1983; Cabrero et al., 1987). However, we do not think that the additional NOR of $M$. trossulus constitutes a latent NOR, because this region is shown to have a different heterochromatin from the NORs of $M$. edulis and $M$. galloprovincialis (chromosomes 6 and 7 are CMA3 positive, whereas chromosome 8 from $M$. trossulus is CMA3 negative). In this sense, we hope that in situ hybridization analysis will clarify this situation.

The existence of an additional NOR in $M$. trossulus allows us to distinguish between this species and $M$. edulis. As both species show the same location and distribution of $\mathrm{C}$ - and CMA3 bands, let us suppose that they have the same evolutionary status. The NOR 
Table 2 Distribution of NORs and CMA3 bands in mussel species

\begin{tabular}{ccccccc}
\hline & \multicolumn{2}{c}{$M$. edulis } & \multicolumn{2}{c}{ M. gallopro } & \multicolumn{2}{c}{ M. trossulus } \\
C. no. & NOR & CMA3 & NOR & CMA3 & NOR & CMA3 \\
\hline 3p,t & - & - & - & $*$ & - & - \\
$6 \mathrm{q}, \mathrm{t}$ & $*$ & $*$ & $*$ & $*$ & $*$ & $*$ \\
$7 \mathrm{q}, \mathrm{t}$ & $*$ & $*$ & $*$ & $*$ & $*$ & $*$ \\
$8 \mathrm{p}, \mathrm{t}$ & - & - & - & - & $*$ & - \\
\hline
\end{tabular}

*, presence of band; - , absence of band; C. no., chromosome number; $p$, band on $p$ arm; $q$, band on $q$ arm; $t$, telomeric band.

of $M$. trossulus has a different heterochromatin status from the other NORs; this is therefore evidence of its uniqueness in this species. The additional CMA 3 band detected in $M$. galloprovincialis and the additional NOR in $M$. trossulus can be considered as chromosomal markers which allow us to identify and distinguish the three types of mussels.

On the other hand, staining with AD/DAPI reveals an absence of banding on the chromosomes of the genus Mytilus. The negative staining observed in the telomeric areas of chromosomes 6 and 7 (Fig. 3g,h) had already been observed by Dixon \& Flavell (1986) in $M$. edulis when they treated the chromosomes with Giemsa staining and/or borate buffer treatment. The existence of these areas, which are coincident with the locations of active NORs, led us to suppose that a correlation between chromatin decondensation and transcriptional activity must exist in these organisms. Furthermore, the fact that these telomeric regions were shown to be $\mathrm{C}$ positive/CMA3 positive/NOR positive/ $\mathrm{AD} / \mathrm{DAPI}$ negative, confirms the absence of AT-rich base pairs, in opposition to the data reported by Dixon \& McFadzen (1987) from $M$. edulis that C positive/ NOR positive regions were AT-rich. The negative response after $Q$ banding seems to reflect the nonexistence of AT-rich regions along the chromosome structure of these organisms. However, taking into account the results obtained after in situ digestion with restriction endonucleases (unpublished data), we could suppose that AT sequences are interspersed in the genomes of these species and, consequently, there could exist a certain degree of genome compartmentalization.

In conclusion, the distribution of C-bands and the existence of chromosomal markers allow us to distinguish these mussel species, and open up new possibilities to clarify the systematic status of the genus Mytilus. We consider that the karyotypic changes which have taken place in the evolution of this genus result from qualitative modifications in the constitutive heterochromatin. We hope that studies of satellite DNA and in situ hybridization will help us to elucidate the role of the constitutive heterochromatin and NORs in the course of karyotypic divergence of the Mytilus species studied in this paper.

\section{Acknowledgements}

We are very grateful to $\mathrm{Dr} \mathbf{H}$. Hummel, who permitted us to use his laboratory at Delta Instituut voor Hydrobiologisch Onderzoek of Yerseke (Holland), and to Miss B. Carril for her technical assistance. This work has been supported by a D.G.I.C.Y.T. 90/0323 (Spain).

\section{References}

AHMED, M. AND SPARKS, A. K. 1970. Chromosome number, structure and autosomal polymorphism in the marine mussels Mytilus edulis and Mytilus californianus. Biol. Bull., 138, 1-13.

CABRERO, J., ALCHE, J. D. AND CAMACHO, J. P. M. 1987. Effects of B chromosomes on the activity of nucleolar organizer regions in the grasshopper Eyprepocnemis plorans: activation of a latent nucleolar organizer region on a B chromosome fused to an autosome. Genome, 29, 116-121.

CAMACHO, J. P. M., CABRERO, J. AND VISERAS, E. 1981. C-heterochromatin variation in the genus Eumigus (Orthoptera: Pamphagoidea). Genetica, 56, 185-188.

CASPERSSON, T., FABER, S., FOLEY, G. E., KUDYNOWSKI, J., MODEST, E. J., SIMONSSON, F., WAGH, U. AND ZECH, L. 1968. Chemical differentiation along metaphase chromosomes. Exp. Cell Res., 49, 219-222.

DIXON, D. R. AND FLAVELL, N. 1986. A comparative study of the chromosomes of Mytilus edulis and Mytilus galloprovincialis. J. Mar. Biol. Ass. U.K., 66, 219-228.

DIXON, D.R. AND MCFADZEN, I. R. B. 1987. Heterochromatin in the interphase nuclei of the common mussel Mytilus edulis $\mathbf{L}$. J. Exp. Mar. Biol. Ecol., 112, 1-9.

DIXON, D. R., McFADZEN, I. R. B. AND SISLEY, K. 1986. Heterochromatic marker regions (nucleolar organisers) in the chromosomes of the common mussel, Mytilus edulis (Mollusca: Pelecypoda). J. Exp. Mar. Biol. Ecol., 97, 205-212.

FERNANDEZ-PIQUERAS, J., RODRIGUEZ CAMPOS, A., SENTIS CASTAÑO, C. AND ROJO GARCIA, E. 1983. Chromosomal location of the active NORs in the Steropleurus martorelli complex. Genetica, 61, 9-12.

GosLING, E.M. (ED.) 1992. The Mussel Mytilus. Elsevier Press, Amsterdam.

HOWELL, W. M. AND BLACK, D. A. 1980. Controlled silver-staining of nucleolus organizer regions with a protective colloidal developer, a 1-step method. Experientia, 36, 1014-1015.

IEYAMA, H. AND INABA, A. 1974. Chromosome numbers of ten species in four families of Pteriomorphia (Bivalvia). Venus, 33, 129-137. 
JOHN, B., KING, M., SCHWEIZER, D. AND MENDELAK, M. 1985. Equilocality of heterochromatin distribution and heterochromatin heterogeneity in acridid grasshoppers. Chromosoma, 91, 185-200.

KING, M. 1980. C-banding studies on Australian hylid frogs: secondary constriction structure and the concept of euchromatin transformation. Chromosoma, 80, 191-217.

KING, M., HONEYCUTT, R. AND CONTRERAS, N. 1986. Chromosomal repatterning in crocodiles: $\mathrm{C}, \mathrm{G}$ and $\mathrm{N}$-banding and the in situ hybridization of $18 \mathrm{~S}$ and $26 \mathrm{~S}$ rRNA cistrons. Genetica, 70, 191-201.

KOEHN, R. K. 1991. The genetics and taxonomy of species in the genus Mytilus. Aquaculture, 94, 125-145.

MACGREGOR, H. C. AND SESSIONS, S. K. 1986. The biological significance of variation in satellite DNA and heterochromatin in newts of the genus Triturus: an evolutionary perspective. Phil. Trans. R. Soc. B, 312, 243-259.

MARTINEZ-EXPÓSITO, M. J., PASANTES, J. J. AND MÉNDEZ, J. 1994. NOR activity in larval and adult mussel Mytilus galloprovincialis L. J. Exp. Mar. Biol. Ecol., 94, 155-165.

MARTínEZ-LAGE, A., GONZÁlEZ-TIZON, A. AND MÉNDEZ, J. 1994. Characterization of different chromatin types in Mytilus galloprovincialis L. after C-banding, fluorochrome and restriction endonuclease treatments. Heredity, 72, 242-249.

MAYR, B., SCHWEIZER, D., MENDELAK, M., KRUTZLER, J., SCHLEGER, W., KALAT, M. AND AUER, H. 1985. Levels of conservation and variation of heterochromatin and nucleolus organizers in the Bovidae. Can. J. Genet. Cytol., 27, 665-682.

MÉNDEZ, J., PASANTES, J. J. AND MARTínEZ-EXPósito, M. J. 1990. Banding pattern of mussel (Mytilus galloprovincialis) chromosomes induced by $2 \times \mathrm{SSC} /$ Giemsa-stain treatment. Mar. Biol., 106, 375-377.
MOYNIHAN, E. P. AND MAHON, G. A. T. 1983. Quantitative karyotype analysis in the mussel Mytilus edulis L. Aquaculture, 33, 301-309.

PASANTES, J., MARTíNEZ-EXPósito, M. J., MARTINEZ-LAGE, A. AND MÉNDEZ, J. 1990. Chromosomes of Galician mussels. J. Moll. Stud., 56, 123-126.

SCHWEIZER, D. 1976. Reverse fluorescent chromosome banding with chromomycin and DAPI. Chromosoma, 58, 307-324.

SCHWEIZER, D. 1980. Simultaneous fluorescent staining of $\mathbf{R}$ bands and specific heterochromatic regions (DA-DAPI bands) in human chromosomes. Cytogenet. Cell Genet., 27, 190-193.

SEED, R. 1968. Factors influencing shell shape in the mussel Mytilus edulis. J. Mar. Biol. Ass. U.K., 48, 561-584.

SKIBINSKI, D. O. F. AND BEARDMORE, J. A. 1979. A genetic study of intergradation between Mytilus edulis and Mytilus galloprovincialis. Experientia, 35, 1442-1444.

SUMNER, A. T. 1972. A simple technique for demonstrating centromeric heterochromatin. Exp. Cell Res., 75, 304-306.

THIRIOT-QUIÉVREUX, C. AND AYRAUD, N. 1982. Les caryotypes de quelques espèces de bivalves et de gastéropodes marins. Mar. Biol., 70, 165-172.

VẢINÖLÄ, R. AND HVILSOM, M. M. 1991. Genetic divergence and a hybrid zone between Baltic and North Sea Mytilus populations (Mytilidae; Mollusca). Biol. J. Linn. Soc., 43, 127-148.

VERMA, R. C. AND RAINA, S. N. 1981. Cytogenetics of Crotolaria. V. Supernumerary nucleoli in C. agatiflora (Leguminosae). Genetica, 56, 75-80.

YosIDA, T. H. AND SAGAI, T. 1975. Variation of C-bands in several subspecies of Rattus rattus. Chromosoma, 50, 283-300. 